\title{
Genetic influence on the associations between IGF-I and glucose metabolism in a cohort of elderly twins
}

\author{
Rikke Beck Jensen ${ }^{1}$, Ajay Thankamony², Klaus K Holst', Joseph A M J L Janssen, Anders Juul', David Dunger², \\ Pernille Poulsen ${ }^{5}$ and Thomas Scheike ${ }^{3}$
}

${ }^{1}$ Department of Growth and Reproduction, Rigshospitalet, University of Copenhagen, Copenhagen, Denmark, ${ }^{2}$ Department of Pediatrics, Addenbrooke's Hospital, University of Cambridge, Cambridge, UK, ${ }^{3}$ Department of Biostatistics, University of Copenhagen, Copenhagen, Denmark, ${ }^{4}$ Department of Internal Medicine, Division of Endocrinology, Erasmus MC, Rotterdam, The Netherlands, and ${ }^{5} \mathrm{Global}$ Development, Novo Nordisk A/S, Soeborg, Denmark

Correspondence should be addressed to $\mathrm{R} B$ Jensen

Email

rikke.beck@dadlnet.dk

\begin{abstract}
Objective: IGF-I may be a marker of later metabolic and cardiovascular disease. The interactions between IGF-I and glucose metabolism are multifactorial, and there is potential confounding from several secondary effects. In this study, we examined the interaction between IGF-I and glucose metabolism in a large cohort of clinically well-characterized elderly twins.

Design: A total of 303 twin pairs of the same gender (606 twins) were included in the study; 125 monozygotic and 178 dizygotic twin pairs.

Methods: A clinical examination including a standard oral glucose tolerance test (OGTT) and anthropometric measurements was performed.

Results: The heritability estimates were high for IGF-I and IGFBP-3 ( $\mathrm{h}_{2}: 0.65$ (95\% Cl: $\left.0.55-0.74\right)$ and $0.71(0.48-0.94)$, respectively) and for insulin secretion $\left(h_{2}=0.56, P<0.0001\right)$, whereas the heritability estimates for insulin sensitivity were low $\left(h_{2}=0.14, P=0.11\right)$. In a multiple regression analysis (adjusting for age, gender and twin status), there was a negative association between IGF-I and insulin sensitivity (B: -0.13 , SE $0.03, P<0.0001$ ) and IGF-I and disposition index (B: -0.05, SE $0.02, P<0.001$ ) in the entire cohort of 606 twins. The associations between IGF-I and both DI and HOMA-S did not differ between the $D Z$ and $M Z$ twins. Forty-five twin pairs were discordant for T2D, but the discordant twins had similar concentrations of IGF-I or IGFBP-3.

Conclusions: There was a high heritability for IGF-I and IGFBP-3, but a low heritability for insulin secretion and insulin sensitivity in a group of elderly twins. In addition, we found a strong negative relationship between IGF-I and insulin sensitivity, which did not seem to be strongly genetically determined.
\end{abstract}

\section{Introduction}

There is emerging evidence that adult height may be a predictor of later disease (1). Around $80 \%$ of the variability of height is genetically determined and GWAS studies have found hundreds of common genetic variants that may determine height (2). However, several environmental factors such as the fetal environment and lifestyle factors also have a great impact on adult height. Insulin and insulin-like growth factor-I (IGF-I) signaling pathways have been suggested to be involved in the association between height and later disease. IGF-I mediates many 
of the actions of growth hormone (GH) on growth, development and cell differentiation, but in addition, IGF-I has distinct metabolic actions (3). Epidemiological studies suggested that lower concentrations of IGF-I may be a biomarker of development of cardiovascular disease (CVD) (4) and diabetes $(5,6,7)$ and other studies found that higher levels of IGF-I were associated with risk of cancer (8). However, recent studies and a large metaanalysis suggest a U-shaped association between IGF-I and all-cause mortality $(9,10)$ as well as cancer $(10)$, CVD (11) and diabetes $(12,13)$ meaning that both subjects with low and high concentrations of IGF-I may have an increased risk of disease. Hepatic insulin plays a role in promoting IGF-I generation $(5,6)$ and the U-shaped association between IGF-I and type 2 diabetes may be due to the changes of beta cell function and thereby insulin secretion over time. Thus, a person with insulin resistance have increased levels of insulin in the portal circulation, and this may drive an increase in hepatic IGF-I secretion, whereas at a later stage when this person develop type 2 diabetes, the insufficient beta cell function may have the reverse effect on IGF-I. Many of the large epidemiological studies include patients with normal glucose tolerance (NGT), impaired glucose tolerance (IGT) and type 2 diabetes (14).

Former twin studies have revealed that the variation of IGF-I and the binding protein IGFBP-3 levels are highly genetically determined with heritability estimates of $63 \%$ and $60 \%$, respectively $(15,16,17)$. Studies of elderly twins showed similar IGF-I levels in the twin pairs (18), which suggests that IGF-I concentrations in each individual may follow a genetically determined trajectory throughout life. In contrast, heritability estimates for the binding protein IGFBP-1, which is regulated by insulin levels, were $36 \%$ and $48 \%$ for insulin, which suggests that IGFBP-1 and insulin levels may be determined by environmental factors such as lifestyle more than genetic factors $(15,19)$.

There is increasing evidence that the GH/IGF-I axis plays a role in normal glucose homeostasis, which may be determined by common genetic pathways. In a population-based cohort, a polymorphism in the IGF1 gene was associated with lower height, lower birth weight, lower serum levels of IGF-I and an increased risk of type 2 diabetes and myocardial infarction $(20,21)$, but controversy exists (22). In addition, a meta-analysis of genome-wide data found that a SNP near the IGF1 gene, that may influence IGF-I expression levels, was associated with fasting insulin and insulin resistance (23).

The strong genetic influence on IGF-I levels throughout life and the associations between genetic variations in the IGF1 gene and insulin could indicate that shared genetic influences are involved in the relation found between IGF-I and glucose metabolism. However, the interactions between IGF-I and insulin sensitivity and secretion are considered multifactorial, and there is potential confounding from numerous secondary effects.

The aim of this study was to assess genetic vs environmental influences on the association between IGF-I parameters, insulin secretion and insulin sensitivity in a large cohort of elderly twins.

\section{Subjects and methods}

\section{Subjects}

The twins who participated in this study were identified through the Danish Twin Register (24), details about the sampling of the cohort have been published in detail previously (25). A total of 303 twin pairs of the same gender (606 twins) were included in the study; 125 monozygotic (men: 62, women: 63) and 178 dizygotic twin pairs (men: 86, women: 92) participated in the clinical examination including a standard oral glucose tolerance test (OGTT) and anthropometric measurements (previously reported in detail $25,26,27,28$ ). The mean age among the twin sample was 67.0 years (range 55-74 years). Zygosity status was established by the similarity method where twins were asked about physical similarity and mistaken identity (29).

As previously described, 79 subjects had T2D defined by either 120 -min glucose $>11.1 \mathrm{mmol} / \mathrm{L}$ or history of diabetes diagnosed at 40 years or older who did not receive insulin treatment within the first year of onset. Of these 79 subjects, 43 (54\%) were diagnosed in the study and 36 had known T2D (mean duration of T2D was 6 year (range: 1-14) for DZ and 8 year (range: 1-19) for MZ). A total of 71 subjects had a 120 -min glucose $>11.1 \mathrm{mmol} / \mathrm{L}$ in the study. In addition, 129 subjects had impaired glucose tolerance (IGT) defined by 120-min glucose $>7.8$ and $<11.1 \mathrm{mmol} / \mathrm{L}$ and 398 subjects had a normal glucose tolerance (NGT) defined by 120-min glucose $<7.8$.

The protocol was approved by the regional ethics committees and the study was conducted according to the principles of the Helsinki declaration.

\section{Methods}

Weight and height were measured with the subject in light clothing without shoes, and body mass index (BMI) was calculated (weight $(\mathrm{kg}) /$ height $\left(\mathrm{m}^{2}\right)$ ). Waist 
circumference was measured using a soft tape midway between the lower ribs and the iliac crest on the standing subjects. Hip circumference was measured over the widest part of the gluteal region, and the waist/hip ratio (WHR) was calculated accordingly.

Subjects underwent a standard $75 \mathrm{~g}$ oral glucose tolerance test (OGTT) after a 10- to 12-h overnight fast. Peripheral venous blood was taken before oral glucose ingestion and $30 \mathrm{~min}$ and $120 \mathrm{~min}$ later.

Plasma glucose concentrations were analyzed by the glucose dehydrogenase oxidation method. Plasma insulin concentrations were measured using a two-site, two-step, time-resolved immunofluoremetric assay (DELFIA) as described previously $(26,28)$. Intra-assay coefficients of variation were $3.6-4.3 \%$ and the inter-assay coefficients of variation were $1.7-3.4 \%$ for plasma insulin.

Plasma insulin-like growth factor-I (IGF-I) and the binding proteins IGFBP-1 and IGFBP-3 were analyzed using the commercially available immunoradiometric assays (Diagnostic Systems Laboratories, Webster, TX, USA). The inter-assay coefficients of variation for total IGF-I, and IGFBP-3 were 8.2 and $1.9 \%$, respectively and the intra-assay coefficients of variation for total IGF-I and IGFBP-3 were 3.4 and 3.9\%, respectively. For IGFBP-1, the intra-assay coefficient of variation was $3.4 \%$ while the inter-assay coefficient of variation was $8.1 \%$.

\section{Calculations}

BMI was computed using the formula, weight $(\mathrm{kg}) /$ height $\left(\mathrm{m}^{2}\right)$.

Insulin sensitivity (IS) was estimated from fasting glucose (average of $-10,-5$ and 0 -min samples) and insulin values by homeostatic model (HOMA) using the HOMA 2 calculator (http://www.dtu.ox.ac.uk/ homacalculator/index.php). Insulinogenic index was calculated from the OGTT as the ratio of the increment in insulin concentration to the increment in glucose after $30 \mathrm{~min}$ (ins30'-ins0'/glu30'-glu0'). Disposition index (DI) provided an estimate of insulin secretion adjusted for the degree of IS and was calculated as the product of IS and insulinogenic index. Matsuda index provided an approximation of whole-body insulin sensitivity from OGTT using fasting glucose and insulin and mean values of glucose and insulin (ISI $\mathrm{Matsuda}_{10}=1000 / \sqrt{ } \mathrm{G}_{0} \mathrm{I}_{0} \mathrm{G}_{\text {mean }} \mathrm{I}_{\text {mean }}$ ).

Impaired glucose intolerance (IGT) was defined according to the current $\mathrm{WHO}$ criteria: fasting venous plasma glucose concentration $<7.8 \mathrm{mmol} / \mathrm{L}$ and a $120 \mathrm{~min}$ post OGTT plasma glucose between 7.8 and $11.1 \mathrm{mmol} / \mathrm{L}$ (ref). Type 2 diabetes (T2D) was defined by either (1) diagnosis of diabetes at the age of 40 years or older and current treatment with antidiabetic agents or diet or (2) meeting the WHO criteria; a fasting venous plasma glucose concentration $\geq 7.8 \mathrm{mmol} / \mathrm{L}$ and/or $2 \mathrm{~h}$ post OGTT venous glucose concentration $\geq 11$.

\section{Statistical analysis}

Heritability $\left(\mathrm{h}^{2}\right)$ expresses the proportion of total variation of a trait attributable to genetic variation and can be estimated by comparing the correlation of a given phenotype within monozygotic twin pairs with the similarity within dizygotic twin pairs. To calculate interclass correlations we computed Pearson correlations for all pairs of variables that were reasonably approximated by the normal distribution and also compared with Spearman rank correlations.

To study this relationship between variables, we used a marginal linear regression using generalized estimating equations for $\mathrm{MZ}$ and $\mathrm{DZ}$ twins separately and combined the estimates to adjust for the possibility that MZ and DZ twins have different correlations. When combining the estimates for MZ and DZ twins, we first checked that estimates were not significantly different; this test is equivalent to comparing the intraclass correlation between the considered variables and is a test for a shared genetic component between the variables.

We used $\mathrm{R}$ and the Mets package for twin modeling.

\section{Results}

\section{Interclass correlations}

Clinical characteristics of the entire cohort divided according to gender are presented in Table 1. Males had significantly higher IGF-I and IGFBP-3 levels $(P<0.0001)$, which is in accordance with former studies (Table 1). Males had significantly lower IGFBP-1 levels $(P<0.001)$ and fasting glucose was significantly higher $(P<0.0001)$, whereas there was no difference in fasting insulin levels or insulin sensitivity determined by HOMA-S (Table 1).

All examined twin pairs (MZ 125; DZ 178) were included in the calculation of interclass correlations. The interclass correlations for IGF-I were $r=0.65$ for MZ and $r=0.33$ for DZ (Fig. 1A and Table 2) and the interclass correlations for IGFBP-3 were $r=0.83$ for MZ and $r=0.47$ for DZ (Fig. 1B and Table 2). The difference in interclass 
Table 1 Clinical characteristics of the 606 twins divided according to gender. Data are presented as median (25-75th percentile)

\begin{tabular}{|c|}
\hline Age (years) \\
\hline BMI $\left(\mathrm{kg} / \mathrm{m}^{2}\right)$ \\
\hline Waist-to-hip ratio \\
\hline Fasting glucose (mmol/L) \\
\hline Fasting insulin (pmol/L) \\
\hline HOMA-S (\%) \\
\hline Disposition index $\left(10^{4 *} \mathrm{pmol}{ }^{*} \min \right)$ \\
\hline IGF-I (nmol/L) \\
\hline IGFBP-3 (mg/L) \\
\hline IGFBP-1 (ng/mL) \\
\hline
\end{tabular}

\begin{tabular}{c}
\hline Women $(n=309)$ \\
\hline $67.3(65.6-69.8)$ \\
$25.5(22.5-28.6)$ \\
$0.80(0.77-0.85)$ \\
$5.6(5.2-6.1)$ \\
$39.0(26.0-55.0)$ \\
$132.5(94-200)$ \\
$8397(5090-14359)$ \\
$16.5(13.1-21.0)$ \\
$3.1(2.6-3.6)$ \\
$36.5(26.2-50.3)$ \\
\hline
\end{tabular}

\begin{tabular}{c} 
Men $(n=292)$ \\
\hline $67.3(65.0-69.4)$ \\
$25.8(23.8-28.0)$ \\
$0.94(0.90-0.98)$ \\
$5.8(5.5-6.3)$ \\
$38.5(28.0-54.3)$ \\
$132.9(91-186)$ \\
$8053(5209-117599)$ \\
$18.9(15.5-23.9)$ \\
$3.4(2.9-3.9)$ \\
$32.6(21.8-42.9)$
\end{tabular}

correlation for IGF-I and IGFBP-3 between the two zygosities were highly significant $(P<0.0001)$ and the heritability estimates were very high; $h_{2}=0.65$ for IGF-I and $\mathrm{h}_{2}=0.71$ for IGFBP-3 (Table 2). There was also high heritability estimates for insulin secretion determined by insulinogenic index $\mathrm{h}_{2}=0.56, P<0.0001$ (Table 2). In contrast, no significant differences in interclass correlations were found for IGFBP-1 (Fig. 1C and Table 2) and insulin sensitivity (HOMA-S) (Fig. 1D and Table 2) and indicating a relatively small genetic contribution to variation of these metabolic variables. The interclass correlations for the interaction between insulin secretion

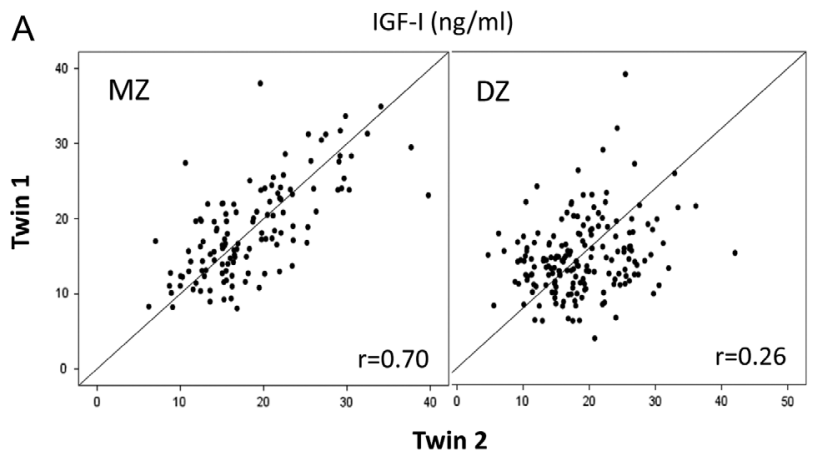

C

Log IGFBP-1

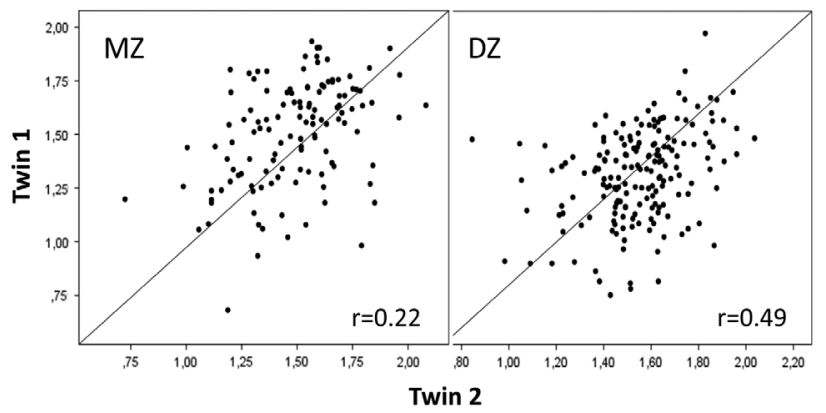

and insulin sensitivity determined by DI were $r=0.44$ for MZ and $r=0.22$ for DZ $(P<0.0001)$ and the heritability estimate was $\mathrm{h}_{2}=0.44$ (Table 2 ).

Birth weight (BW) was available in 123 twin pairs (52 MZ and $71 \mathrm{DZ}$ twins), but there was no information on gestational age. The interclass correlations for BW were $r=0.66$ for $\mathrm{MZ}$ and $r=0.55$ for DZ leading to a low heritability $\left(\mathrm{h}_{2}=0.21\right)$.

All calculations of heritability were adjusted for age and gender for all variables, this did not alter any of the results and the unadjusted results are therefore presented.

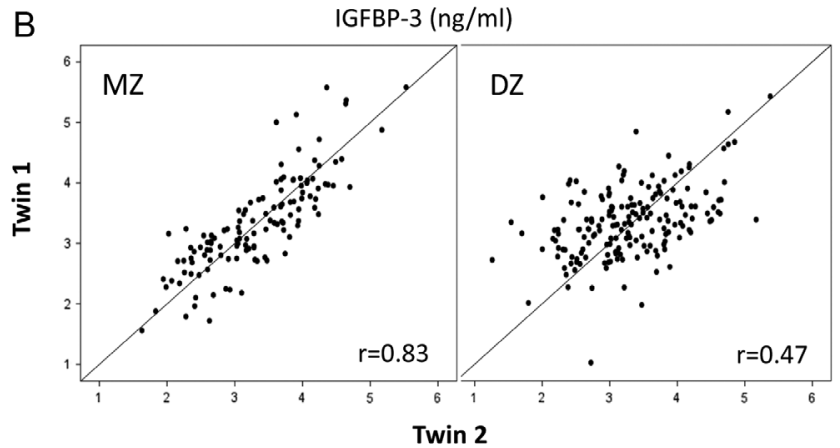

$\mathrm{D}$

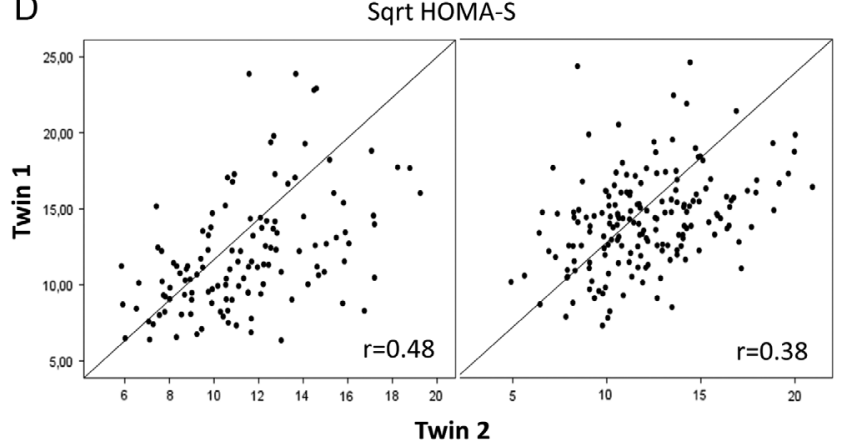

Figure 1

Correlations in serum concentrations of IGF-I (A), IGFBP-3 (B), IGFBP-1 (C) and HOMA-S (D) for MZ and DZ pairs of twins. 
Table 2 Interclass correlations and heritability estimates for anthropometric and metabolic variables in monozygotic ( $n=125)$ and dizygotic $(n=178)$ twin pairs. Data are presented as interclass correlation or heritability estimates (95\% confidence interval).

\begin{tabular}{|c|c|c|c|c|}
\hline \multirow[b]{2}{*}{ Phenotype } & \multicolumn{2}{|c|}{ Interclass correlation } & \multirow[b]{2}{*}{$P$ value } & \multirow{2}{*}{$\begin{array}{c}\text { Heritability } \\
2(r m z-r d z) \\
\end{array}$} \\
\hline & $\mathrm{MZ}$ & $\mathrm{DZ}$ & & \\
\hline IGF-I & $0.65(0.54-0.73)$ & $0.33(0.27-0.37)$ & $<0.0001$ & $0.65(0.55-0.74)$ \\
\hline IGFBP-3 & $0.83(0.77-0.87)$ & $0.47(0.35-0.57)$ & $<0.0001$ & $0.71(0.48-0.94)$ \\
\hline IGFBP-1 & $0.38(0.24-0.31)$ & $0.38(0.23-0.50)$ & 0.85 & $0.02(-0.34-0.37)$ \\
\hline Insulin secretion & $0.56(0.43-0.68)$ & $0.28(0.22-0.34)$ & $<0.0001$ & $0.56(0.44-0.68)$ \\
\hline Insulin sensitivity (HOMA-S) & $0.47(0.34-0.54)$ & $0.40(0.27-0.32)$ & 0.11 & $0.14(-0.19-0.47)$ \\
\hline Disposition index & $0.44(0.30-0.56)$ & $0.22(0.15-0.28)$ & $<0.0001$ & $0.44(0.31-0.57)$ \\
\hline
\end{tabular}

\section{Concordance}

In the entire cohort of MZ twins (125 twin pairs), 45 twin pairs ( $n=90$ twins) were discordant for T2D (i.e. one twin with T2D and the other twin with non-diabetic glucose tolerance). As expected, there were significant differences in the parameters related to glucose metabolism outcomes between twin pairs discordant for T2D (data not shown). In contrast, there were no significant differences in IGF-I concentrations; median 16.65 (25-75\% range; $14.9-22.3$ ) vs 17.17 (14.0-25.1) $P=0.84$ and IGFBP-3 concentrations; median 3.33 (2.9-3.9) vs 3.29 (2.7-3.9) between those with T2D and the non-diabetic twins, respectively. The group of non-diabetic twins included twins with IGT, however, excluding the group with IGT did not alter the results.

\section{Associations between IGF-I and glucose metabolism}

In the entire cohort of twins, IGF-I was positively correlated to fasting insulin ( $\beta$ : 0.20 , SE $0.23, P<0.0001$ ) and fasting glucose $(\beta$ : 0.14, SE $0.08, P<0.0001)$ and negatively correlated to insulin sensitivity (HOMA-S) $(\beta:-0.21$, SE $0.23, P<0.0001)$ (Fig. 2$)$ and DI $(\beta:-0.14$, SE $0.41, P=0.001)$, whereas there was no correlation between IGF-I and insulin secretion (insulinogenic index) $(\beta$ : -0.03, SE $0.38, P=0.52)$. In addition, IGF-I was positively correlated to IGFBP-3 ( $\beta: 0.51$, SE 0.67 , $P<0.0001)$ and negatively correlated to IGFBP-1 $(\beta$ : -0.38 , SE 0.21, $P<0.0001$ ).

When adjusting the analyses for age, gender and twin status in a multiple regression analysis IGF-I remained negatively associated to insulin sensitivity determined by HOMA-S (B: $-0.13,95 \% \mathrm{CI}$ SE $0.03, P<0.0001$ ), the Matsuda index (B: -0.11 , SE $0.03, P<0.0001)$ and DI (B: -0.05, SE $0.02, P<0.001$ ) in the entire cohort of 606 twins. In contrast, there was no association between IGF-I and insulin secretion determined by insulinogenic index $(P=0.45)$. The associations between IGF-I and insulin, glucose, HOMA-S and DI did not differ between the
DZ and MZ twins. All the results were consistent after excluding the subjects with IGT and T2D.

\section{Discussion}

In this large cohort of elderly twins, we confirmed a strong heritability of IGF-I and IGFBP-3 as found in former studies on both newborn and elderly twins $(15,16,30)$ and a strong heritability for insulin secretion and disposition index, whereas the heritability for insulin sensitivity and IGFBP-1 were small and non-significant. In the 45 twin pairs, who were discordant for type 2 diabetes, metabolic parameters varied greatly, but the concentrations of IGF-I were similar among the twin with $\mathrm{T} 2 \mathrm{D}$ and the twin without. However, in the entire cohort of twins, IGF-I was negatively associated with insulin sensitivity (adjusted for age, gender and twin status), which did not differ between MZ and DZ twins. The lack of effect of zygosity on this relationship could indicate that alterations in IGF-I levels associated with abnormalities in glucose metabolism may be mediated primarily by environmental rather than genetic factors. However, a limitation of our twin study is that the study was a cross-sectional study and therefore cannot give evidence of causality but can generate and confirm hypotheses. Furthermore, our study included participants with defined differences in glucose metabolism at the time of the study (NGT, IGT and T2D twins). The relation between levels of IGF-I and insulin sensitivity does not necessarily imply causation, it may instead be a possible 'reverse causation' in which the levels of IGF-I may reflect alterations caused by insulin resistance or by a compensatory mechanism.

IGF-I and insulin share significant structural homology and downstream pathways, their receptors are homologous and form heterodimers, which can bind both ligands. IGF-I secretion is mainly regulated by GH stimulation and nutrition, but findings in prospective studies determined that hepatic insulin plays a role in promoting IGF-I generation $(5,6,31,32)$. However, in 


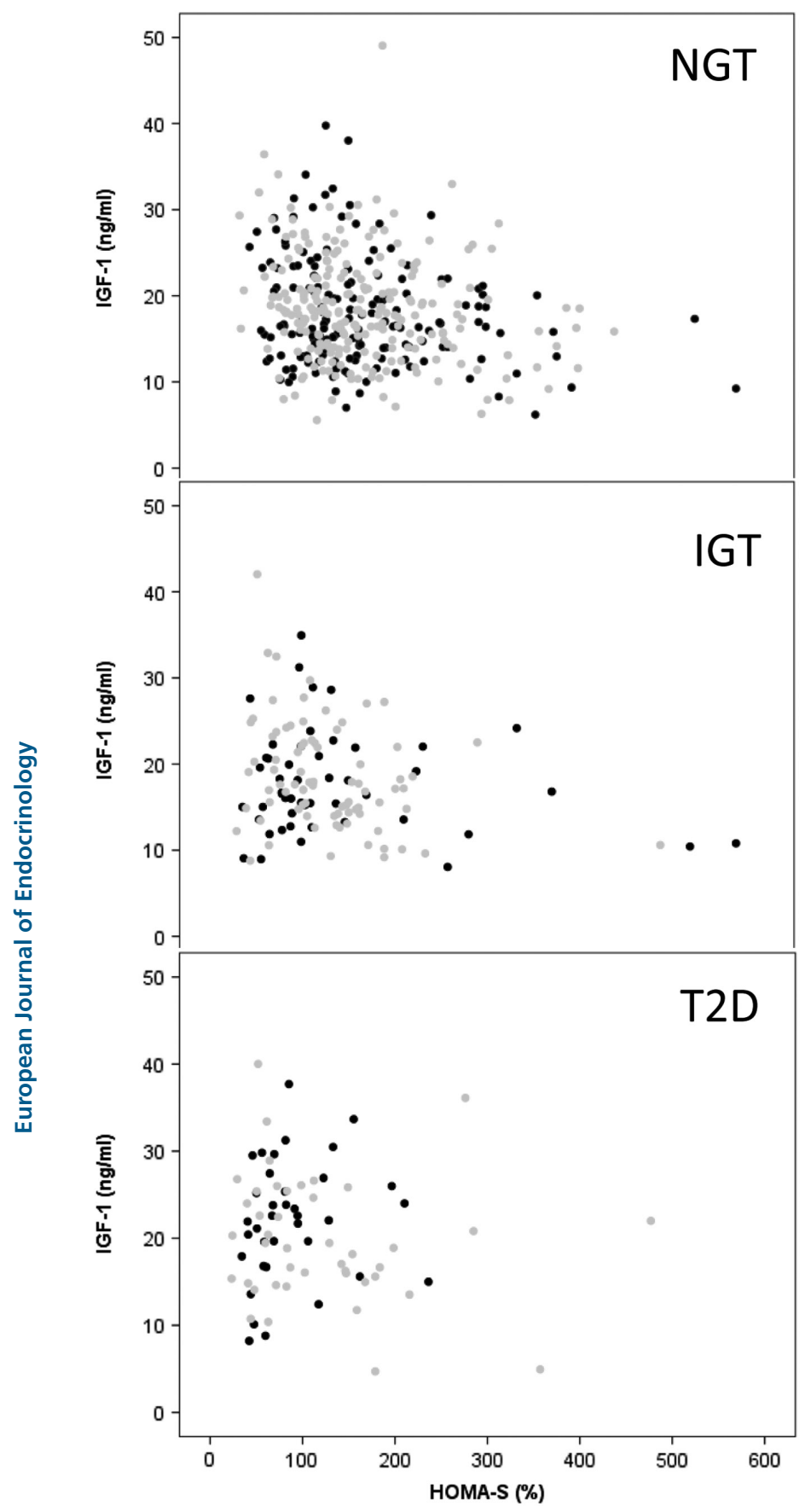

Figure 2

Association between IGF-I and HOMA-S in twins with normal glucose tolerance, NGT (top panel), impaired glucose tolerance, IGT (middle panel) and type 2 diabetes, T2D (lower panel). Black dots are monozygotic twins and gray dots are dizygotic twins.

this cohort of twins, there were no significant differences in IGF-I concentrations between twins discordant for type 2 diabetes and the positive association between IGF-I and insulin sensitivity remained even after excluding twins with IGT and type 2 diabetes. Furthermore, IGF-I circulates in the blood bound to six high-affinity binding proteins (IGFBPs). Insulin controls the concentration of IGFBP-1 because it downregulates the hepatic production of IGFBP-1 (33) and therefore increased insulin levels due to insulin resistance will reduce IGFBP-1 levels and thereby increase IGF-I bioavailability. In the current twin study, we found a positive association between IGF-I and fasting insulin but no association between IGF-I and insulin secretion. In contrast, IGF-I was negatively associated with insulin sensitivity, which was somewhat controversial as former studies have shown a positive association between the IGF-I concentration and insulin sensitivity $(32,34)$. However, a recent cross-sectional study in a large population discovered a U-shaped association between serum IGF-I levels and insulin resistance (14). In addition, analysis of two prospective cohort studies including more than 7000 non-diabetic subjects revealed an association between low IGF-I at baseline and an increased incidence of diabetes at follow-up, but this association became insignificant after adjustment for metabolic markers such as abdominal obesity, hypertension, glucose and dyslipidemia (35). Thus, the interaction between IGF-I and insulin sensitivity is complex and many of the large cohort studies are confounded by including subjects over a large span of age, BMI and metabolic status.

The physiological role of IGF-I on insulin sensitivity, observed from studies on IGF-I therapy revealing that IGF-I improves insulin sensitivity in normal subjects as well as in patients with GHD (36), could be another possible mechanism explaining the negative relation between IGF-I and insulin sensitivity found in our study. Treatment with rh-IGF-I in patients with diabetes improves insulin sensitivity significantly, insulin requirements are reduced and control of glucose and dyslipidemia is generally improved $(37,38)$. In addition, a former study on healthy non-obese male volunteers selected by IGF-I levels showed that those with IGF-I levels in the lowest quartile of normal distribution had lower fasting insulin levels and greater hepatic insulin sensitivity compared to those in the highest quartile (39). Furthermore, we and others have shown that children born small for gestational age (SGA) who had higher IGF-I concentrations had a lower insulin sensitivity and a poor growth response to rhGH treatment (40, 41). To confirm this association, we used the Mendelian randomization approach in a group of SGA children and found an independent association between alleles coding for insulin sensitivity and first year height velocity and 
IGF-I responses to rhGH suggesting a causal link between insulin sensitivity and IGF-I (42).

Metabolic markers may be part of the causal pathway in the relation between IGF-I and diabetes, but it is also possible that IGF-I is truly confounded by obesity because obesity has a major blunting effect on the GH secretion, whereas circulating IGF-I levels will stay unaffected (43). Patients with T2D have a broad range of serum IGF-I concentrations and multiple variables may interact to regulate IGF-I levels such as inflammatory cytokines, decreases in hepatic insulin action due to insulin resistance, concomitant changes in IGF-binding proteins and the effects of obesity on GH secretion. In the current study, we found higher levels of IGF-I in the entire group of twins with T2D compared to those with normal glucose tolerance, whereas there was no difference in IGF-I levels between those with IGT and normal glucose tolerance. When comparing the monozygotic twin pairs discordant of IGT and T2D, they had similar IGF-I levels and there was no difference in BMI between the groups. A large meta-analysis showed a high heritability of $72 \%$ for type 2 diabetes (44). However, a recent study of more than 4000 monozygotic twin pairs discordant for BMI revealed that twins with higher BMI had an increased risk of onset of type 2 diabetes, which suggests that environmental factors are important as well (45).

Adult height has been proposed as a predictor of later disease and a large meta-analysis among more than one million people found that increased height was associated with increased risk of cancer but decreased risk of cardiovascular disease (1). The variability of height is mainly genetically determined (2), but several environmental factors such as the intrauterine environment, nutrition and other lifestyle factors may have a great impact on adult height. Insulin and IGF-I signaling pathways have been suggested to play an important role in the relation between height and later disease and previous findings suggest that each individual may follow a genetically determined trajectory throughout life. In our twin study, we confirmed that the high heritability of IGF-I, IGFBP-3 and insulin secretion persist into late in life, which confirms that the circulating levels of IGF-I and insulin may maintain relatively constant throughout life. A better way to study the difference in genetic and environmental factors is to include twin pairs reared apart or together to determine non-shared environmental influences. A Swedish study on 248 pairs of middle aged and elderly twins found that the phenotypic association between IGF-I and insulin and IGFBP-1 were caused by environmental effects (30); however, this study did not examine insulin secretion or insulin sensitivity.

In conclusion, we confirm the high heritability of IGFI, IGFBP-3 and insulin secretion, which suggests that the levels of IGF-I in each individual may follow a trajectory throughout life, whereas the genetic factors played a smaller role for insulin sensitivity. IGF-I and insulin sensitivity were negatively associated and zygosity did not influence this association, which suggest an important role of environmental factors driving the relationship, but long-term longitudinal studies are needed to explore this in detail.

\section{Declaration of interest}

The authors declare that there is no conflict of interest that could be perceived as prejudicing the impartiality of this study.

\section{Funding}

This research did not receive any specific grant from any funding agency in the public, commercial or not-for-profit sector.

\section{References}

1 Wormser D, Di Angelantonio E, Kaptoge S, Wood AM, Gao P, Sun Q, Walldius G, Selmer R, Monique Verschuren WM, Bueno-de-Mesquita $\mathrm{HB}$ et al. Adult height and the risk of causespecific death and vascular morbidity in 1 million people: individual participant meta-analysis. International Journal of Epidemiology 2012 41 1419-1433. (https://doi.org/10.1093/ije/dys086)

2 Wood AR, Esko T, Yang J, Vedantam S, Pers TH, Gustafsson S, Chu AY, Estrada K, Luan J, Kutalik Z et al. Defining the role of common variation in the genomic and biological architecture of adult human height. Nature Genetics 201446 1173-1186. (https://doi.org/10.1038/ ng.3097)

3 Clemmons DR. Metabolic actions of insulin-like growth factor-I in normal physiology and diabetes. Endocrinology and Metabolism Clinics of North America 201241 425-443. (https://doi.org/10.1016/j. ecl.2012.04.017)

4 Juul A, Scheike T, Davidsen M, Gyllenborg J \& Jorgensen T. Low serum insulin-like growth factor I is associated with increased risk of ischemic heart disease: a population-based case-control study. Circulation 2002106 939-944. (https://doi.org/10.1161/01. CIR.0000027563.44593.CC)

5 Colao A, Di Somma C, Cascella T, Pivonello R, Vitale G, Grasso LF, Lombardi G \& Savastano S. Relationships between serum IGF1 levels, blood pressure, and glucose tolerance: an observational, exploratory study in 404 subjects. European Journal of Endocrinology 2008159 389-397. (https://doi.org/10.1530/EJE-08-0201)

6 Sandhu MS, Heald AH, Gibson JM, Cruickshank JK, Dunger DB \& Wareham NJ. Circulating concentrations of insulin-like growth factor-I and development of glucose intolerance: a prospective observational study. Lancet 2002359 1740-1745. (https://doi. org/10.1016/S0140-6736(02)08655-5)

7 Sesti G, Sciaqua A, Cardellini M, Marini M, Maio R, Vatrano M, Succurro E, Lauro R, Federici M \& Perticone F. Plasma concentration of IGF-I is sensitivity in subjects with different. Diabetes Care $2005 \mathbf{2 8}$ 120-125. (https://doi.org/10.2337/diacare.28.1.120)

8 Major JM, Laughlin GA, Kritz-Silverstein D, Wingard DL \& Barrett-Connor E. Insulin-like growth factor-I and cancer mortality 
in older men. Journal of Clinical Endocrinology and Metabolism 201095 1054-1059. (https://doi.org/10.1210/jc.2009-1378)

9 Burgers AM, Biermasz NR, Schoones JW, Pereira AM, Renehan AG, Zwahlen M, Egger M \& Dekkers OM. Meta-analysis and doseresponse metaregression: circulating insulin-like growth factor I (IGF-I) and mortality. Journal of Clinical Endocrinology and Metabolism 201196 2912-2920. (https://doi.org/10.1210/jc.2011-1377)

10 Svensson J, Carlzon D, Petzold M, Karlsson MK, Ljunggren O, Tivesten A, Mellstrom D \& Ohlsson C. Both low and high serum IGF-I levels associate with cancer mortality in older men. Journal of Clinical Endocrinology and Metabolism 201297 4623-4630. (https:// doi.org/10.1210/jc.2012-2329)

11 van Bunderen CC, van Nieuwpoort IC, van Schoor NM, Deeg DJ, Lips P \& Drent ML. The association of serum insulin-like growth factor-I with mortality, cardiovascular disease, and cancer in the elderly: a population-based study. Journal of Clinical Endocrinology and Metabolism 201095 4616-4624. (https://doi.org/10.1210/jc.20100940)

12 Friedrich N, Thuesen B, Jrøgensen T, Juul A, Spielhagen C, Wallaschofksi H \& Linneberg A. The association between IGF-I and insulin resistance: a general population study in Danish adults. Diabetes Care 201235 768-773. (https://doi.org/10.2337/dc11-1833)

13 Schneider HJ, Friedrich N, Klotsche J, Schipf S, Nauck M, Völzke H, Sievers C, Pieper L, März W, Wittchen HU et al. Prediction of incident diabetes mellitus by baseline IGF1 levels. European Journal of Endocrinology 2011164 223-229. (https://doi.org/10.1530/EJE-100963)

14 Friedrich N, Thuesen B, Jorgensen T, Juul A, Spielhagen C, Wallaschofksi H \& Linneberg A. The association between IGF-I and insulin resistance: a general population study in Danish adults. Diabetes Care 201235 768-773. (https://doi.org/10.2337/dc11-1833)

15 Harrela M, Koistinen H, Kaprio J, Lehtovirta M, Tuomilehto J, Eriksson J, Toivanen L, Koskenvuo M \& Leinonen P. Genetic and environmental components of interindividual variation in circulating. Society 199698 2612-2615. (https://doi.org/10.1172/ JCI119081)

16 Hong M \& Lee VM. Insulin and insulin-like growth factor-1 regulate tau phosphorylation in cultured human neurons. Journal of Biological Chemistry 1997272 19547-19553. (https://doi.org/10.1074/ jbc.272.31.19547)

17 Stone J, Folkerd E, Doody D, Schroen C, Treloar SA, Giles GG, Pike MC, English DR, Southey MC, Hopper JL et al. Familial correlations in postmenopausal serum concentrations of sex steroid hormones and other mitogens: a twins and sisters study. Journal of Clinical Endocrinology and Metabolism 200994 4793-4800. (https:// doi.org/10.1210/jc.2009-0713)

18 Harrela M, Koistinen H, Kaprio J, Lehtovirta M, Tuomilehto J, Eriksson J, Toivanen L, Koskenvuo M, Leinonen P, Koistinen R et al. Genetic and environmental components of interindividual variation in circulating levels of IGF-I, IGF-II, IGFBP-1, and IGFBP-3. Journal of Clinical Investigation 199698 2612-2615. (https://doi.org/10.1172/ JCI119081)

19 Hong Y, Brismar K, Hall K, Pedersen NL \& de Faire U. Associations between insulin-like growth factor-I (IGF-I), IGF-binding protein-1, insulin and other metabolic measures after controlling for genetic influences: results from middle-aged and elderly monozygotic twins. Journal of Endocrinology 1997153 251-257. (https://doi.org/10.1677/ joe.0.1530251)

20 Vaessen N, Janssen JA, Heutink P, Hofman A, Lamberts SW, Oostra BA, Pols HA \& van Duijn CM. Association between genetic variation in the gene for insulin-like growth factor-I and low birthweight. Lancet 2002359 1036-1037. (https://doi.org/10.1016/ S0140-6736(02)08067-4)

21 Vaessen N, Heutink P, Janssen JA, Witteman JC, Testers L, Hofman A, Lamberts SW, Oostra BA, Pols HA \& van Duijn CM. A polymorphism in the gene for IGF-I: functional properties and risk for type 2 diabetes and myocardial infarction. Diabetes 200150 637-642. (https://doi.org/10.2337/diabetes.50.3.637)

22 Frayling TM, Hattersley AT, McCarthy A, Holly J, Mitchell SM, Gloyn AL, Owen K, Davies D, Smith GD \& Shlomo Ben Y. A putative functional polymorphism in the IGF-I gene: association studies with type 2 diabetes, adult height, glucose tolerance, and fetal growth in U.K. populations. Diabetes 200251 2313-2316. (https://doi. org/10.2337/diabetes.51.7.2313)

23 Dupuis J, Langenberg C, Prokopenko I, Saxena R, Soranzo N, Jackson AU, Wheeler E, Glazer NL, Bouatia-Naji N, Gloyn AL et al. New genetic loci implicated in fasting glucose homeostasis and their impact on type 2 diabetes risk. Nature Genetics 201042 105-116. (https://doi.org/10.1038/ng.520)

24 Kyvik KO, Green A \& Beck-Nielsen H. The new Danish Twin Register: establishment and analysis of twinning rates. International Journal of Epidemiology 199524 589-596. (https://doi.org/10.1093/ije/24.3.589)

25 Poulsen P, Vaag AA, Kyvik KO, Moller Jensen D \& Beck-Nielsen H. Low birth weight is associated with NIDDM in discordant monozygotic and dizygotic twin pairs. Diabetologia 199740 439-446. (https://doi.org/10.1007/s001250050698)

26 Poulsen P, Kyvik KO, Vaag A \& Beck-Nielsen H. Heritability of type II (non-insulin-dependent) diabetes mellitus and abnormal glucose tolerance--a population-based twin study. Diabetologia 199942 139-145. (https://doi.org/10.1007/s001250051131)

27 Poulsen P, Levin K, Beck-Nielsen H \& Vaag A. Age-dependent impact of zygosity and birth weight on insulin secretion and insulin action in twins. Diabetologia 200245 1649-1657. (https://doi.org/10.1007/ s00125-002-0983-6)

28 Poulsen P, Vaag A, Kyvik K \& Beck-Nielsen H. Genetic versus environmental aetiology of the metabolic syndrome among male and female twins. Diabetologia 200144 537-543. (https://doi. org/10.1007/s001250051659)

29 Magnus P, Berg K \& Nance WE. Predicting zygosity in Norwegian twin pairs born 1915-1960. Clinical Genetics 198324 103-112. (https://doi.org/10.1111/j.1399-0004.1983.tb02220.x)

30 Pedersen L. Insulin. Journal of Clinical Endocrinology and Metabolism 199681 1791-1797.

31 Ong KK, Petry CJ, Emmett PM, Sandhu MS, Kiess W, Hales CN, Ness AR \& Dunger DB. Insulin sensitivity and secretion in normal children related to size at birth, postnatal growth, and plasma insulin-like growth factor-I levels. Diabetologia 200447 1064-1070. (https://doi.org/10.1007/s00125-004-1405-8)

32 Sandhu MS, Gibson JM, Heald AH, Dunger DB \& Wareham NJ. Association between insulin-like growth factor-I: insulin-like growth factor-binding protein-1 ratio and metabolic and anthropometric factors in men and women. Cancer Epidemiology, Biomarkers and Prevention 200413 166-170. (https://doi.org/10.1158/1055-9965.EPI130-3)

33 Lee PD, Giudice LC, Conover CA \& Powell DR. Insulin-like growth factor binding protein-1: recent findings and new directions. Proceedings of the Society for Experimental Biology and Medicine 1997 216 319-357. (https://doi.org/10.3181/00379727-216-44182)

34 Sierra-Johnson J, Romero-Corral A, Somers VK, Lopez-Jimenez F, Mälarstig A, Brismar K, Hamsten A, Fisher RM \& Hellénius ML. IGF-I/ IGFBP-3 ratio: a mechanistic insight into the metabolic syndrome. Clinical Science 2009116 507-512. (https://doi.org/10.1042/ CS20080382)

35 Schneider HJ, Friedrich N, Klotsche J, Schipf S, Nauck M, Volzke H, Sievers C, Pieper L, Marz W, Wittchen HU et al. Prediction of incident diabetes mellitus by baseline IGF1 levels. European Journal of Endocrinology 2011164 223-229. (https://doi.org/10.1530/EJE-100963)

36 LeRoith D \& Yakar S. Mechanisms of disease: metabolic effects of growth hormone and insulin-like growth factor 1. Nature Clinical Practice: Endocrinology and Metabolism 20073 302-310. (https://doi. org/10.1038/ncpendmet0427) 
37 Regan FM, Williams RM, McDonald A, Umpleby AM, Acerini CL, O'Rahilly S, Hovorka R, Semple RK \& Dunger DB. Treatment with recombinant human insulin-like growth factor (rhIGF)-I/rhIGF binding protein-3 complex improves metabolic control in subjects with severe insulin resistance. Journal of Clinical Endocrinology and Metabolism 201095 2113-2122. (https://doi.org/10.1210/jc.20092088)

38 Clemmons DR, Sleevi M, Allan G \& Sommer A. Effects of combined recombinant insulin-like growth factor (IGF)-I and IGF binding protein-3 in type 2 diabetic patients on glycemic control and distribution of IGF-I and IGF-II among serum binding protein complexes. Journal of Clinical Endocrinology and Metabolism 200792 2652-2658. (https://doi.org/10.1210/jc.2006-2699)

39 Thankamony A, Capalbo D, Marcovecchio ML, Sleigh A, Jørgensen SW, Hill NR, Mooslehner K, Yeo GSH, Bluck L, Juul A et al. Low circulating levels of IGF-1 in healthy adults are associated with reduced $\beta$-cell function, increased intramyocellular lipid, and enhanced fat utilization during fasting. Journal of Clinical Endocrinology and Metabolism 201499 2198-2207. (https://doi. org/10.1210/jc.2013-4542)

40 Jensen RB, Thankamony A, O'Connell SM, Salgin B, Kirk J, Donaldson M, Ivarsson SA, Söder O, Roche E, Hoey $\mathrm{H}$ et al. Baseline IGF-I levels determine insulin secretion and insulin sensitivity during the first year on growth hormone therapy in children born small for gestational age. Results from a North European Multicentre Study (NESGAS) on behalf of the NESGAS group. Hormone Research in Paediatrics 201380 38-46. (https://doi. org/10.1159/000353438)
41 De ZF, Ong K, van HM, Mohn A, Woods K \& Dunger D. High-dose growth hormone $(\mathrm{GH})$ treatment in non-GH-deficient children born small for gestational age induces growth responses related to pretreatment GH secretion and associated with a reversible decrease in insulin sensitivity. Journal of Clinical Endocrinology and Metabolism 200287 148-151. (https://doi.org/10.1210/jcem.87.1.8293)

42 Jensen RB, Thankamony A, Day F, Scott RA, Langenberg C, Kirk J, Donaldson M, Ivarsson SA, Söder O, Roche E et al. Genetic markers of insulin sensitivity and insulin secretion are associated with spontaneous postnatal growth and response to growth hormone treatment in short SGA children: the North European SGA Study (NESGAS). Journal of Clinical Endocrinology and Metabolism 2014100 E503-E507. (https://doi.org/10.1210/jc.2014-3469)

43 Hjortebjerg R, Flyvbjerg A \& Frystyk J. Insulin growth factor binding proteins as therapeutic targets in type 2 diabetes. Expert Opinion on Therapeutic Targets 201418 209-224. (https://doi.org/10.1517/14728 222.2014.858698)

44 Willemsen G, Ward KJ, Bell CG, Christensen K, Bowden J, Dalgård C, Harris JR, Kaprio J, Lyle R, Magnusson PKE et al. The concordance and heritability of type 2 diabetes in 34,166 twin pairs from international twin registers: the discordant twin (DISCOTWIN) consortium. Twin Research and Human Genetics 201518 762-771. (https://doi.org/10.1017/thg.2015.83)

45 Nordström P, Pedersen NL, Gustafson Y, Michaëlsson K \& Nordström A. Risks of myocardial infarction, death, and diabetes in identical twin pairs with different body mass indexes. JAMA Internal Medicine 2016176 1522. (https://doi.org/10.1001/ jamainternmed.2016.4104)

Received 19 September 2017

Revised version received 14 November 2017

Accepted 20 November 2017 